\title{
Solid Waste Management Practice in a Less Developed Urban Setting: A Case Study
}

Keywords: Waste management; Disposal; Environment; Nigeria; Kano

\begin{abstract}
This paper presents the findings of a case study that explores the existing situation of solid waste management and disposal practices in metropolitan Kano; the largest urban setting in northern Nigeria. The study was developed using various data sourced from field surveys and existing literature. It reveals the indiscriminate nature of the handling and disposal of solid waste in Kano metropolis, which it identifies as unhygienic, unsustainable and poses significant threats to the environment and public health. Therefore, it is recommended that it is imperative to manage efficiently and effectively the waste generated in the area, should the overall goal of sustainable development be achieved. This should include waste minimisation at the source resource recovery, reuse and recycling.
\end{abstract}

\section{Introduction}

Recently, the rapid growth of human population, urbanisation and changing standards of living, especially in less-developed regions, have resulted in a considerable increase in the exploitation of natural resources, accompanied by the production of large quantities of waste of diverse characteristics. For example, it is estimated that more than 25 million tonnes of solid waste (SW) is generated annually in Nigeria [1] by its 182 million inhabitants [2]. The SW generated needs to be managed properly to protect the life-supporting environment, should the overall goal of sustainable development be achieved. However, it is well documented that the issue of poor SW management is among the primary environmental and social challenges facing many parts of the world; especially the urban areas of less-developed regions [3-8].

Many towns across Nigeria are littered randomly with piles of SW that are, for the most part, mixed with human and animal excreta, often obstructing access roads, urban drainage and rivers [8-10]. This widespread practice is unsustainable and contributes significantly to numerous health and environmental problems. While such issues can be easily generalised, addressing them requires, to a large extent, a location-specific approach due to the significant variation in the quantity and diversity of waste generated in different areas.

According to many sources [10-12], waste characteristics depend primarily on several factors that are peculiar to each community; such as, consumption pattern, climatic condition, culture and economic prosperity. Therefore, delivering an effective waste management strategy requires an adequate understanding of the existing situation of waste generation and management, in addition to other sociocultural and economic conditions of the community in focus. This is the basis for conducting this research. The paper aims to contribute towards providing more knowledge and understanding of the challenges faced by SW management practice in Kano, which is a typical cosmopolitan centre in Nigeria.

\section{Journal of}

Environmental Studies

\author{
Ahmed F Ali ${ }^{* *}$, Adamu I Tanko ${ }^{1}$ and Abdulsalami S \\ Kovo $^{2}$

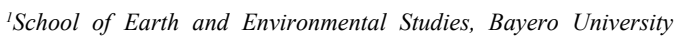 \\ Kano, Nigeria \\ ${ }^{2}$ Department of Chemical Engineering, Federal University of \\ Technology, Minna, Nigeria \\ *Address for Correspondence \\ Ahmed F Ali, School of Earth and Environmental Studies, \\ Bayero University Kano, Nigeria, Tel: +2348152420139; E-mail: \\ ahmadpate@yahoo.co.uk \\ Submission: 03 December, 2016 \\ Accepted: 03 April, 2017 \\ Published: 10 April, 2017 \\ Copyright: ๑ 2017 Ali AF. This is an open access article distributed under \\ the Creative Commons Attribution License, which permits unrestricted \\ use, distribution, and reproduction in any medium, provided the original \\ work is properly cited.
}

\section{Framework for SW Management in Nigeria}

The fundamentals of Nigeria's environmental policy are laid out in the 1999 Constitution of the Federal Republic. The overall administration and enforcement of the environmental policies in the country are vested on the Federal Ministry of Environment. Although the constitution stipulates that the responsibility for delivering SW management services rests with the (Local Government Authorities (LGA), it has empowered each state government and LGA nationwide to choose to establish its own environmental protection organisation that will work to protect and improve the environment. Moreover, state governments are empowered to legislate laws for the protection and improvements to the environment it controls. It is on that basis that the various state governments and the Federal Capital Territory (FCT) established environmental agencies administering SW management within their boundaries. In Abuja, for example, the FCT authorities have issued the Abuja Environmental Protection Board (SW Control/Environmental Monitoring) Regulations 2005 that primarily governs SW control in the federal capital. Other examples are: the Lagos State Environmental Protection Agency Law issued in

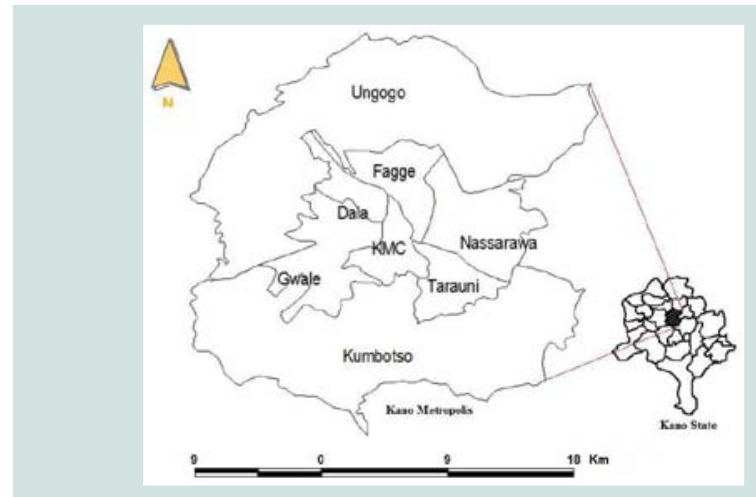

Figure 1: Map of Kano Metropolis [16]. 


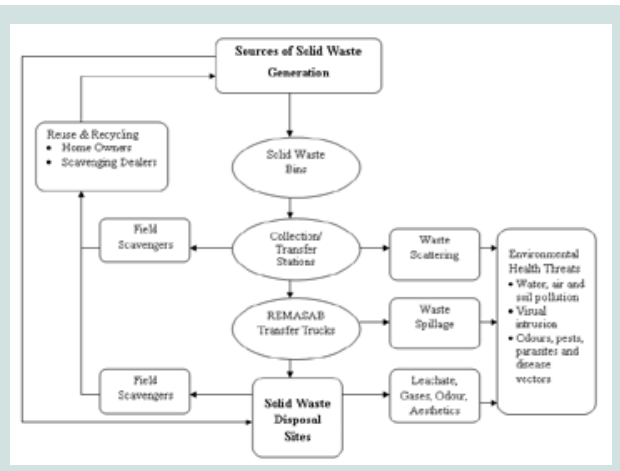

Figure 2: Components of SW management in Kano.

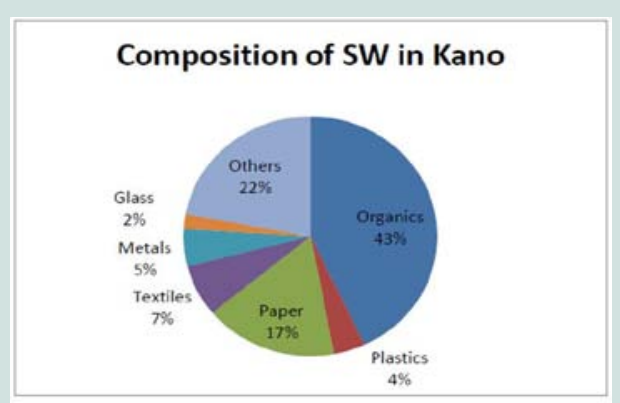

Figure 3: Composition of SW in Kano metropolis.

Lagos state, and the establishment Refuse Management and Sanitation Board (REMASAB) in Kano state. These public organisations oversee all affairs relating to SW management in their areas. While they also participate in collection and disposals themselves, some operate a number of public, private partnerships with other private operators.

\section{Research Methods and the Study Area}

This research is a descriptive survey of the situation of SW management in Kano, Nigeria. The data used in this work were sourced from interviews and field observations supported by secondary data collected from published and unpublished materials. Kano is positioned in the north-central boundary of Nigeria, located approximately $840 \mathrm{~km}$ from the beginning of the Sahara Desert and some $1,140 \mathrm{~km}$ from the Atlantic coast [13]. Figure 1 presents a map of Kano metropolis. With a population of nearly 4 million; it is the largest urban area in northern Nigeria. The metropolis has a substantial range of industrial and commercial activities [14]. It consists of 8 local government areas, covering a land mass of about $500 \mathrm{~km}^{2}$ located between longitude $8^{\circ}$ and $9^{\circ}$ east and latitude $10^{\circ}$ and $12^{\circ}$ north [15]. The results generated in this research are presented in the next section.

\section{Results and Discussion}

\section{Waste management situation in Kano}

The practice of SW management in Kano metropolis is typical of many urban areas in less-developed regions. Several authors have characterised the practice by a wide range of challenges, including inadequate collection coverage, improper transportation methods, and poor practice of final disposal; for example, open dumping and burning without any consideration of pollution prevention and environmental control [6,8,10,12,17-19].

As the population of Kano grows rapidly, at a rate of about 3.5\% per annum [19], so do urbanisation and living standards. Naturally, these are accompanied by the production of large volumes of waste of varying characteristics. Over time, the waste generation has increased considerably in both quantity and diversity, and has exceeded the available provisions for its management [12]. Consequently, heaps of waste materials, often mixed with human and animal excreta, end up being disposed of indiscriminately in various locations, including roadsides, uncompleted buildings, open spaces, drains, streams, ponds and rivers across the metropolis.

This indiscriminate disposal is highly unsustainable and leads to the various environmental and public health issues already affecting the region. These include widespread flooding, the transmission and spread of preventable diseases, and damage to the aesthetic beauty of the areas $[11,13,20,21]$. The following sections describe the different aspects of waste management in Kano, while Figure 2 summarises the key components of the existing waste management system.

\section{SW generation and composition}

The amount of SW generated in any society relates strongly to its population dynamics. In Kano metropolis, an estimated rate of $0.56 \mathrm{~kg} / \mathrm{capita}$ of waste is generated daily [22]. As the second most populous city in Nigeria, with nearly 4 million inhabitants, this translates into a massive volume; the management of which presents an ongoing challenge to the population and local authorities.

Figure 3 illustrates the average compositional characteristics of SW produced in Kano. On closer inspection, the composition varies markedly between different parts of the area [23]. Also, a notable variation in waste characteristics between high and low-income areas in the metropolis was observed. For instance, the higher-income neighbourhood of GRA produces more than twice the amounts of recyclables (such as paper, plastics, metals/cans and bottles) compared with its lower-income counterparts. This concurs with the suggestions made in many sources of literature [such as 4,11,13], which highlight the revenue and economic prosperity of societies as impacting enormously on the quantity and characteristics of its generated waste.

The high percentage of organic and biodegradable contents and

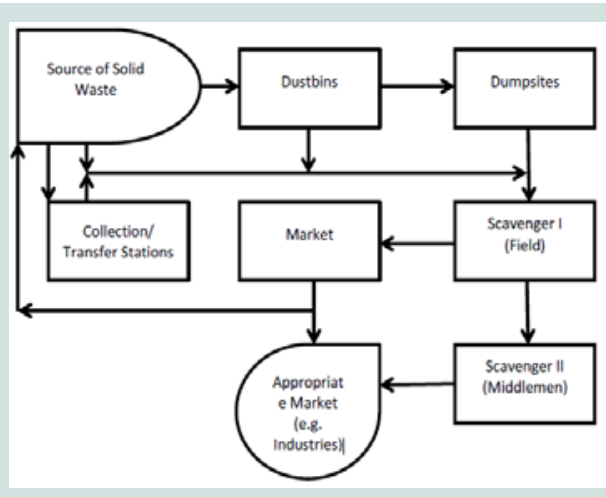

Figure 4: Typical informal recycling pathways in Nigeria. 
low recyclables, such as plastics, metals and glass, in the SW is typical of waste composition in many urban areas in less-developed regions. Moreover, the tradition of informal segregation at the source of recyclable materials for reuse and informal recycling by scavengers contributes to the reduced number of recyclables in the waste stream.

\section{Waste collection and transportation}

The centrality of collection and transportation in waste management systems cannot be over-emphasised. In Kano metropolis, the institutional responsibility of delivering waste management services, from collection through to disposal, lies with the Refuse Management and Sanitation Board (REMASAB). This is the organisation under the state government that collects waste materials from across the metropolis and disposes it at allocated sites. It also engages some private operators to deliver waste management services under a public private participation arrangement. It is noteworthy that similar types of organisations are typically responsible for providing waste management services in other urban areas across Nigeria.

It was observed that the public-sector waste collectors are involved mainly in waste movement from transfer centres to the disposal sites, while the private operators offer door-to-door collections in high-income neighbourhoods, public establishments and industrial areas. Additionally, when REMASAB requires additional service capacity in waste transfer, the private companies become involved on a contractual basis. However, despite these arrangements, waste collection and transportation in the metropolis remains grossly inadequate and inefficient, to the extent that it is offered to only a small proportion of the population, leaving many piles of waste materials uncollected and disposed of across the area. According to REMASAB, funding remains a major challenge to their wider coverage and effective service delivery. However, it could be argued that the budgetary allocation to the organisation, when managed efficiently, could yield a better outcome than what prevails.

Poor accessibility to many areas in the slums and unplanned neighbourhoods further exacerbates these limitations. The waste collectors use different types of vehicles, including compactor trucks; pay loaders; bucket lifters; bulldozers, mini trucks; tippers; tractors; and open-back vans. However, poor maintenance and lack of adequate operational knowledge continue to hinder the ability of the operators to deliver effective and efficient services.

\section{Resource recovery and recycling}

Although there is a sizeable quantity of recyclable materials in the waste generated in Kano metropolis, the entire region lacks proper recycling programmes $[11,24]$. This research observes that the limited number of recyclables, such as metal cans, plastics, bottles and papers, are salvaged informally by scavengers both at the source, during storage, at collection centres and in the various disposal sites across the region.

Figure 3 illustrates a typical recycling pathway in the study area, which is characteristic of most parts of the country. Traditionally, informal recycling activities have been practised in the region for several years as a means of making a living, driven mainly by poverty. Recently, however, such activities have transformed into big business due to the emergence of a huge market in the industrial sector. For example, these activities provide a source of cheap raw materials for plastic industries. Moreover, many of the industries engage scavengers in sourcing informally for recyclables that will be further processed to meet the market requirements.

\section{Waste disposal practice}

Currently, SW materials in Kano metropolis and most parts of the region are disposed of in a poorly-controlled manner primarily in open dumps without any form of treatment [10-12,18,20,22,24]. This practice is not sustainable and has the potential to cause severe environmental degradation that may affect the health and well-being of the local population. The situation is further complicated by the indiscriminate locations of the REMASAB authorised disposal sites in areas that appear environmentally sensitive. This research reveals that disposal sites have all been located, primarily, based on convenience and plan for land reclamation, rather than any regard to environmental sustainability or public health. A good approach to facilitate the process of achieving sustainable waste disposal practice in the metropolis is enhanced participation of organised private sector in the provision, operations and management of disposal sites. This is because, even when collection coverage is enhanced to cover most neighbourhoods, the apparent lack of appropriate disposal sites jeopardises the entire waste management system.

This research observes that approximately 180 waste disposal sites exist in metropolitan Kano, most of which are located in slums and poor neighbourhoods. It should be noted that most these sites are neither authorised nor regulated by the responsible agency, and have originated primarily due to the poor coverage of waste collection. The locations of these disposal sites place more pressure on the environment, health and the prevailing poor living conditions of those living in the vicinity. These neighbourhoods are known to be densely populated with even more deficient infrastructure than other parts of the metropolis. This disposal practice reflects the weak institutional and operational capacity of the responsible authority in delivering proper waste management in the area and the government will benefit from allowing private participation and recognising SW management as a thriving business.

\section{Conclusion}

The manner in which SW is managed currently in Kano metropolis is a cause for much concern. As the population increases rapidly, on one hand, coupled with changing standards of living, there is an increasingly large amount of waste materials being produced. Conversely, the existing management systems are weak and disorganised, and the available collection and disposal facilities are not being developed at the same pace to be able to cope with the pressing needs. A visible reflection of the situation takes the form of indiscriminately disposed heaps of SW, often mixed with human and animal excreta, piling up in the streets, incomplete buildings and open spaces, as well as blocking drains, streams and rivers. This practice is highly unsustainable and poses considerable risk to the environment and public health.

Therefore, it is recommended that these issues are addressed adequately to ensure the overall goal of sustainable development is achieved in Kano and other cities across the region. The current 
ISSN: 2471-4879

disposal practice should move away from open dumping towards disposal that is more controlled and sanitary. Moreover, a paradigm shift is required from the existing strategy to a more sustainable approach that involves waste minimisation at the source, resource recovery and recycling. Additionally, private sector participation should be organised and coordinated to enhance the efficiency and effectiveness of service delivery. Furthermore, it is imperative that the authorities allocate sufficient funding to equipment, infrastructure, maintenance, workforce development and remediation strategies and implementation.

\section{References}

1. Njoku N, Lamond J, Everett G, Manu P (2015) An overview of municipal solid waste management in developing and developed economies: Analysis of practices and contributions to urban flooding in Sub-Saharan Africa. In: $12^{\text {th }}$ International Postgraduate Research Conference Proceedings, Manchester UK, pp. 200- 212.

2. National Population Commission, Nigeria (2017) Official website.

3. Buenrostro O, Bocco G (2003) Solid waste management in municipalities in Mexico: goals and perspectives. Resour Conserv Recycl 39: 251-263.

4. Medina M (2003) Globalisation, development, and municipal solid waste management in third world cities. El Colegio de la FronteraNorte, Tijuana, Mexico

5. Vidanaarachchi CK, Yuen ST, Pilapitiya S (2006) Municipal solid waste management in the Southern Province of Sri Lanka: problems, issues and challenges. Waste Manag 26: 920-930.

6. Henry RK, Yongsheng Z, Jun D (2006) Municipal solid waste management challenges in developing countries--Kenyan case study. Waste Manag 26: 92-100.

7. Amusan AA, Ige DV, Olawale R (2005) Characteristics of soils and crops' uptake of metals in municipal waste dump sites in Nigeria. J Hum Ecol 17: 167-171.

8. Ali AF, Young RJ (2013) Effects of waste disposal sites on groundwater quality in Urban Kano, Nigeria. Proceedings Sardinia 2013, Fourteenth International Waste Management and Landfill Symposium. S. Margherita di Pula, Cagliari, Italy. CISA Publisher, Italy.

9. Agunwanba JC (2003) Analysis of scavengers' activities and recycling in some cities of Nigeria. Environ Manage 32: 116-127.

10. Imam A, Mohammed B, Wilson DC, Cheeseman CR (2008) Solid waste management in Abuja, Nigeria. Waste Manag 28: 468-472.

11. Ogwueleka T (2009) Muncipal solid waste characteristics and management in Nigeria. J Environ Health Sci Eng 6: 173-180.

12. Bichi MH, Amatobi DA (2013) Characterization of household solid wastes generated in Sabon-gari area of Kano in Northern Nigeria. Am J Res Commun 1: 165-171.

13. Okunola OJ, Uzairu A, Gimba CE, Ndukwe GI (2012) Assessment of Gaseous Pollutants along High Traffic Roads in Kano, Nigeria. Int J Environ Sustain 1.

14. Maconachie R (2007) Urban growth and land degradation in developing cities: change and challenges in Kano, Nigeria. Ashgate Publishing: Aldershot, UK.

15. Ahmed M, Muhammad N, Mohammed MU, Idris Y (2013) A GIS-Based analysis of police stations distributions in Kano Metropolis. IOSR J Comput Eng 8: 72-78.

16. Isa UF, Yusuf AY (2011) Spatial distribution and utilization of intercontinental bank automated teller machines in Kano Metropolis. Eur J Sci Res 52: 44-51.

17. Cointreau S (2006) Occupational and environmental health issues of solid waste management: special emphasis on middle and lower-income countries. World Bank, Washington, DC.

18. Nabegu AB (2010) An analysis of municipal solid waste in Kano Metropolis, Nigeria. J Hum Ecol 31: 111-119.

19. Ibrahim AM (2014) How far is too far? The facts and figures on human population in Kano state. Int J Hum Soci Sci Inven 3: 61-64.

20. Taiwo AA (2009) Waste management towards sustainable development in Nigeria: A case study of Lagos state. Int NGO J 4: 173-179.

21. Ali AF, Young RJ (2014) An assessment of groundwater contamination around a solid waste disposal site in Kano, Nigeria. Waste Manag Environ VII 180: 7 .

22. Amber I, Daniel MK, Nicholas G (2012) Municipal waste in Nigeria generation, characteristics and energy potential of solid. Asian J Eng Sci Technol 2: 8488.

23. Nabegu AB (2013) Application of One Way Analysis of Variance (ANOVA) in exploring municipal solid waste characteristics in Kano Metropolis, Northwestern Nigeria. Greener J Sci Eng Technol Res 3: 062-067.

24. Mukhtar M (2008) Analysis of plastic waste recycling in Kano Nigeria. Unpublished PhD Thesis submitted to Department of Economics, Bayero University Kano, Nigeria. 